\title{
ESTADO DO CONHECIMENTO: PRÁTICAS PEDAGÓGICAS, FORMAÇÃO E DESENVOLVIMENTO PROFISSIONAL DOCENTE DO PROFESSOR DA EDUCAÇÃO SUPERIOR
}

\author{
ESTATE OF KNOWLEDGE: PEDAGOGICAL PRACTICES, TRAINING AND \\ PROFESSIONAL DEVELOPMENT TEACHING TEACHER OF HIGHER \\ EDUCATION
}

\author{
ESTADO DEL CONOCIMIENTO: PRÁCTICAS PEDAGÓGICAS, FORMACIÓN Y \\ DESARROLLO PROFESIONAL DOCENTE DEL PROFESOR DE LA EDUCACIÓN \\ SUPERIOR
}

\author{
Vania Maria de Oliveira Vieira \\ E-mail: vaniacamila@uol.com.br \\ Marilene Ribeiro Resende \\ E-mail: marilene.resende@,uniube.br \\ Valeska Guimarães Rezende da Cunha \\ E-mail: valeska.guimaraes@uniube.br \\ Camilla de Oliveira Vieira \\ E-mail: gestor.administracao@uniube.br \\ Universidade de Uberaba - UNIUBE
}

\begin{abstract}
RESUMO
Este estudo integra uma pesquisa maior que busca identificar e compreender as representações sociais dos professores iniciantes de três universidades do Triângulo Mineiro, sobre formação e desenvolvimento profissional docente na educação superior. De caráter bibliográfico e com o propósito de constituir-se em um estudo preliminar, esta pesquisa realizou um Estado do Conhecimento, compreendido como uma metodologia que permite mapear produções científicas relativas a um determinado tema. Tomou como objetivo geral verificar o que já foi produzido e pesquisado sobre a temática "formação e desenvolvimento profissional docente na educação superior", para, assim, subsidiar teoricamente os estudos da pesquisa maior. Para a realização do estudo, utilizaram-se como fonte de pesquisa artigos científicos publicados na plataforma Scielo, no período de agosto a outubro de 2017, a partir dos termos indutores: a) Desenvolvimento Profissional Docente do Professor da Educação Superior; b) A Formação Continuada de Professores no Ensino Superior; e c) Práticas Pedagógicas na Educação Superior. Desta busca, encontraram-se 55 artigos, dos quais, após leitura dos respectivos resumos, foram selecionados 25. A análise dos dados contou com o auxílio do software Eramutq, para uma compressão maior dos resultados das pesquisas. Esses resultados evidenciam um consenso de que, para a maioria das pesquisas, as dificuldades ou fragilidades formativas dos professores dizem respeito à compreensão e desenvolvimento das práticas pedagógicas no Ensino Superior.
\end{abstract}

Palavras-chaves: Estudo do conhecimento. Formação e desenvolvimento profissional docente. Práticas Pedagógicas. Ensino Superior.

\footnotetext{
ABSTRACT

This study integrates a larger research that seeks to identify and understand the social representations of the beginning teachers of three universities of the Triângulo Mineiro, about training and professional development in higher education. With a bibliographic character and with the purpose of constituting a preliminary study, this research carried out a State of Knowledge, understood as a methodology that allows to map scientific productions related to a certain theme. It has as a general objective to verify what has already been produced and researched on the theme "teacher training and professional development in higher education", in order to theoretically subsidize larger research studies. In order to carry out the study, scientific articles published on the Scielo platform were used as research sources from August to October 2017, based on the inductive terms: a) Professional Development of the Professor of Higher Education; b) Continuing Education of Teachers in Higher Education; and c) Pedagogical Practices in Higher Education. From this search, 55 articles were found, of which, after reading the respective summaries, 25 were selected. Data analysis was supported by Eramutq
} 


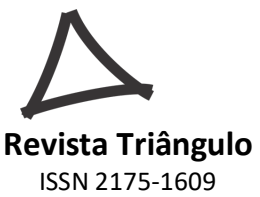

software, for a better compression of the results of the research. These results show a consensus that, for most researches, the difficulties or formative weaknesses of teachers are related to the understanding and development of pedagogical practices in Higher Education.

Keywords: Knowledge study. Teacher training and professional development. Pedagogical practices. Higher education.

\section{RESUMEN}

Este estudio integra una investigación mayor que busca identificar y comprender las representaciones sociales de los profesores principiantes de tres universidades del Triángulo Minero, sobre formación y desarrollo profesional docente en la educación superior. De carácter bibliográfico y con el propósito de constituirse en un estudio preliminar, esta investigación realizó un Estado del Conocimiento, comprendido como una metodología que permite mapear producciones cientificas relativas a un determinado tema. Tomó como objetivo general verificar lo que ya fue producido e investigado sobre la temática "formación y desarrollo profesional docente en la educación superior", para, así, subsidiar teóricamente los estudios de la investigación mayor. Para la realización del estudio, se utilizaron como fuente de investigación artículos científicos publicados en la plataforma Scielo, en el periodo de agosto a octubre de 2017, a partir de los términos inductores: a) Desarrollo Profesional Docente del Profesor de Educación Superior; b) La formación continuada de profesores en la enseñanza superior; $y$ c) Prácticas pedagógicas en la educación superior. De esta búsqueda, se encontraron 55 artículos, de los cuales, después de leer los respectivos resúmenes, fueron seleccionados 25 . El análisis de los datos contó con la ayuda del software Eramutq, para una compresión mayor de los resultados de las encuestas. Estos resultados evidencian un consenso de que, para la mayoría de las investigaciones, las dificultades o fragilidades formativas de los profesores se refieren a la comprensión y desarrollo de las prácticas pedagógicas en la Enseñanza Superior.

Palabras claves: Estudio del conocimiento. Formación y desarrollo profesional docente. Prácticas pedagógicas. Enseñanza superior.

\section{INTRODUÇÃO}

Nos últimos anos, a docência no ensino superior e o desenvolvimento profissional dos professores que nela atuam têm sido motivo de preocupação de diversas instituições e de pesquisadores que tratam do tema. Para muitos autores, grande parte dos professores do ensino superior não foi formada para ser educador, chegando à universidade sem nenhuma formação pedagógica. Afirmam, ainda, que a atividade docente exige um preparo específico e não pode sintetizar apenas no domínio do conteúdo da disciplina. Assim, o tema "a formação e desenvolvimento profissional docente na educação superior”, reconhecido como um dos fatores básicos para a qualidade da aprendizagem nesse nível de ensino, constitui, nesta pesquisa, o objeto de estudo. E para início da investigação, foi realizado um Estado do Conhecimento a partir de leituras e fichamentos de artigos encontrados na plataforma Scielo.

Concordamos com Novikoff (2010), quando afirma que o estado do conhecimento deve ser a primeira etapa para o desenvolvimento de uma pesquisa. A autora acresce, ainda, que essa etapa deve considerar dois desafios. O primeiro, com relação ao ineditismo de um trabalho, isto é, verificar o que foi pesquisado para não repetir estudos já produzidos - o que

\begin{tabular}{|l|l|l|l}
\hline v.11 & n.2
\end{tabular}




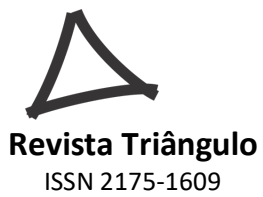

permite validar o objeto e o problema da pesquisa. O segundo diz respeito ao subsídio teórico para a coleta e análise dos dados - ora, o estado do conhecimento permite indicar caminhos metodológicos para a realização de uma pesquisa. E foi esse o propósito deste estudo preliminari: verificar o que já foi produzido e pesquisado sobre a temática "formação e desenvolvimento profissional docente na educação superior" e subsidiar-se teoricamente em estudos já realizados para coleta e análise dos dados.

\section{REFERENCIAL TEÓRICO}

A fundamentação teórica para a realização deste estudo buscou subsídios em autores do campo da metodologia científica, que elucidam os caminhos metodológicos para construção de pesquisas bibliográficas denominadas Estado do Conhecimento. Para compor o corpus da pesquisa, utilizamos os 25 artigos selecionados no site Scielo, já anunciadas. São eles:

Quadro 01: Títulos e autores dos artigos selecionados no site Scielo a partir do termo indutor "Desenvolvimento Profissional Docente do Professor da Educação Superior".

\begin{tabular}{|l|l|}
\hline $\mathbf{N}^{\mathbf{0}}$ & Autor e título do artigo \\
\hline $01^{1}$ & $\begin{array}{l}\text { MORGADO, J. C. Avaliação e Qualidade do Desenvolvimento Profissional Docente: Que } \\
\text { Relação? }\end{array}$ \\
\hline 02 & $\begin{array}{l}\text { DELGADO, C. B; GÁMEZ, A.N. Formador de la educación superior técnico profesional: } \\
\text { Percepciones sobre su trabajo docente }\end{array}$ \\
\hline 03 & $\begin{array}{l}\text { PRYJMA, M. F; OLIVEIRA, O.S. O Desenvolvimento Profissional dos Professores da } \\
\text { Educação Superior: reflexões sobre a aprendizagem para a docência. }\end{array}$ \\
\hline 04 & $\begin{array}{l}\text { FREIRE, L.I.F; FERNANDEZ, C. O professor universitário novato: tensões, dilemas e } \\
\text { aprendizados no início da carreira docente. }\end{array}$ \\
\hline 05 & $\begin{array}{l}\text { VOSGERAU, D. S. R; ORLANDO, E. A.; MEYER, P. Produtivismo Acadêmico e suas } \\
\text { repercussões no desenvolvimento profissional de professores universitários. }\end{array}$ \\
\hline
\end{tabular}

Fonte: dados da pesquisa

Quadro 02: Títulos e autores dos artigos selecionados no site Scielo a partir do termo indutor "A Formação Continuada de Professores no Ensino Superior".

\footnotetext{
${ }^{1} \mathrm{O}$ número do artigo será mantido em todo o texto para facilitar a correspondência de informações.
} 


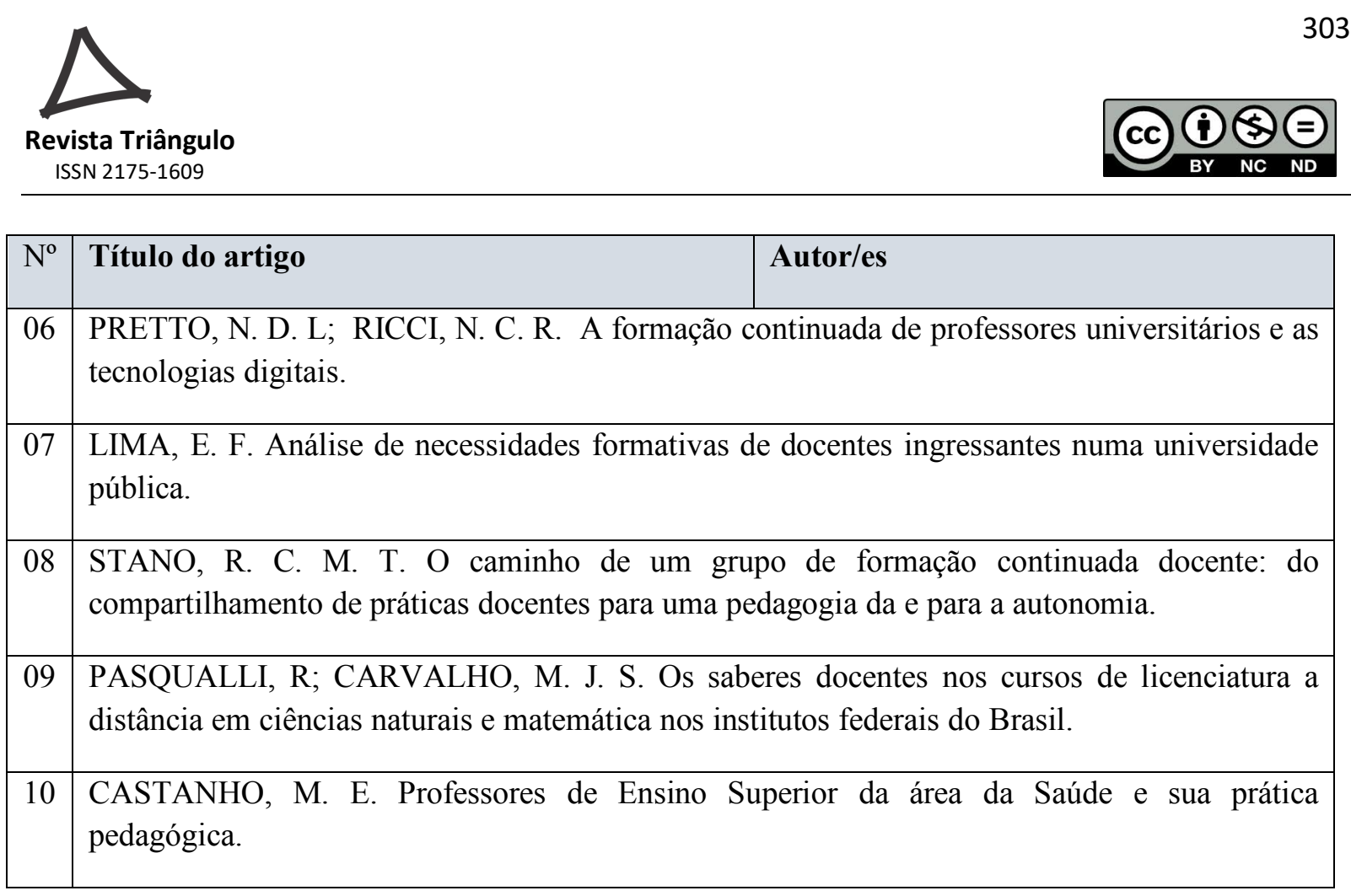

Fonte: dados da pesquisa

Quadro 03: Títulos e autores dos artigos selecionados no site Scielo a partir do termo indutor "Práticas Pedagógicas na Educação Superior"

\begin{tabular}{|c|l|l|}
\hline $\mathbf{N}^{\mathbf{0}}$ & Título do artigo & Autor/es \\
\hline 11 & $\begin{array}{l}\text { PRADO, M. L; VELHO, M. B; ESPÍNDOLA, D. S; SOBRINHO, S.H; BACKES, V. M. S. } \\
\text { Arco de Chales Maguerez: Refletindo Estratégias de Metodologia Ativa na Formação de } \\
\text { Profissionais de Saúde }\end{array}$ \\
\hline 12 & $\begin{array}{l}\text { VINCENZI, A. Concepciones de enseñanza y su relación com las prácticass docentes: um estúdio } \\
\text { com professores universitários. }\end{array}$ \\
\hline 13 & $\begin{array}{l}\text { MARCON,D; GRAÇA, A. B. S; NASCIMENTO, J. V. Critérios para a implementação de } \\
\text { práticas pedagógicas na formação inicial em educação fisica e implicações no conhecimento } \\
\text { pedagógico do conteúdo dos futuros professores. }\end{array}$ \\
\hline 14 & $\begin{array}{l}\text { GAZZINELLI, M. F;SOUZA, V; FONSECA, R. M .G. S; FERNANDES, M. M.; CARNEIRO, } \\
\text { A. C. L. L; GODINHO, L. K. Educational group practices in primary care: interaction between } \\
\text { professionals, users and knowledge. }\end{array}$ \\
\hline 15 & \begin{tabular}{l} 
LIMA, V. V. Espiral construtivista: uma metodologia ativa de ensino-aprendizagem. \\
\hline 16
\end{tabular} & $\begin{array}{l}\text { MAGALHÃES, L. K. C; AZEVEDO, L. C. S. S. Formação continuada e suas implicações: entre } \\
\text { a lei e o trabalho docente }\end{array}$ \\
\hline 17 & $\begin{array}{l}\text { DAMIANCE, P. R. M; TONETE, V. L, P; DAIBEM, A. M. L; FERREIRA, M. L. S. M; } \\
\text { BASTOS, J. R. M. Formação para o SUS: uma análise sobre as concepções e práticas } \\
\text { pedagógicas em saúde coletiva. }\end{array}$ \\
\hline 18 & \begin{tabular}{l} 
DANIERVELIN, R. M; PEREIRA, D. R. C. Inovação e abertura no discurso das práticas \\
\hline
\end{tabular}
\end{tabular}




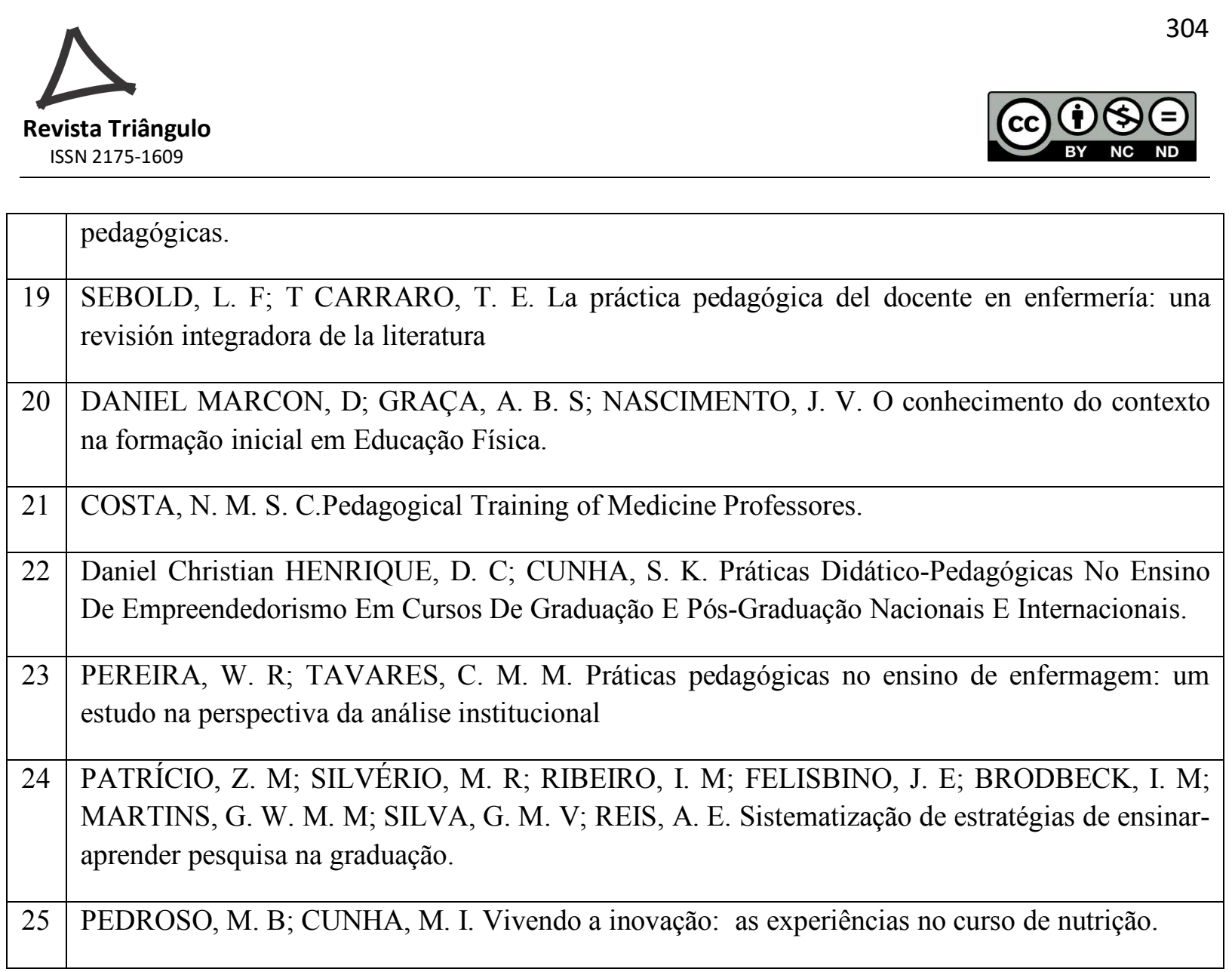

Fonte: dados da pesquisa.

\section{MATERIAIS E MÉTODOS}

Esta pesquisa, de caráter bibliográfico e de cunho quanti-qualitativo, realizou um Estado do Conhecimento, compreendido como uma metodologia que permite mapear produções científicas relativas a um determinado tema. Nas palavras de Morosinia e Fernandes (2014, p. 155), o Estado do Conhecimento é “a identificação, registro, categorização que levem à reflexão e síntese sobre a produção científica de uma determinada área, em um determinado espaço de tempo, congregando periódicos, teses, dissertações e livros sobre uma temática específica".

Destacam como característica importante deste estudo a contribuição para a construção de uma nova produção.

Nesta mesma linha de pensamento, para Ferreira (2002, p. 257), o Estado do Conhecimento tem o desafio de: “[...] mapear e de discutir uma certa produção acadêmica em diferentes campos do conhecimento, tentando responder que aspectos e dimensões vêm sendo destacados e privilegiados em diferentes épocas e lugares [...]”. 
Neste estudo, utilizamos como fonte de pesquisa artigos científicos publicados na plataforma Scielo, no período de agosto a outubro de 2017, a partir dos termos indutores: a) Desenvolvimento Profissional Docente do Professor da Educação Superior; b) A Formação Continuada de Professores no Ensino Superior; e c) Práticas Pedagógicas na Educação Superior.

Inicialmente, acessamos o Google (https://www.google.com.br/) e pesquisamos por "Scielo Busca Avançada". Em seguida, clicamos no link (http://search.scielo.org/advanced/?lang=pt) e escrevemos, respectivamente, em momentos distintos, os termos de busca no espaço disponibilizado. Não foi necessário utilizar nenhum filtro para a busca dos artigos. Dessa busca, como pode ser observado na tabela 01, encontramos 55 artigos, dos quais, após leitura dos respectivos resumos, selecionamos 25 . Os demais foram descartados por não tratar, especificamente, do objeto de estudo da nossa pesquisa.

Tabela 01: número de produções encontradas e selecionadas a partir da utilização dos termos de busca

\begin{tabular}{l|c|c}
\hline Termos de busca & Encontrados & Selecionados \\
\hline $\begin{array}{l}\text { a) Desenvolvimento Profissional Docente do Professor da Educação } \\
\text { Superior }\end{array}$ & 7 & 5 \\
\hline b) A Formação Continuada de Professores no Ensino Superior & 13 & 5 \\
\hline c) Práticas Pedagógicas na Educação Superior. & 35 & 15 \\
\hline TOTAL & 55 & 25 \\
\hline
\end{tabular}

Fonte: dados da pesquisa.

De posse dos 25 artigos selecionados, realizamos um estudo com o propósito de identificar e compreender: as palavras-chave, o problema, o objetivo e os resultados apresentados.

Para isso, algumas questões conduziram o desenvolvimento deste estudo: O que dizem as pesquisas sobre a formação e desenvolvimento profissional docente do professor no Ensino Superior? A formação e desenvolvimento profissional do docente no Ensino Superior influenciam as práticas pedagógicas desenvolvidas por eles? As pesquisas identificaram as dificuldades ou fragilidades formativas dos professores? 


\section{ANÁLISE DOS DADOS}

\subsection{O que dizem as pesquisas sobre as práticas pedagógicas, formação e desenvolvimento profissional docente do professor no Ensino Superior?}

\subsubsection{As palavras-chave}

Para compreender o que mostram as 25 pesquisas selecionadas para compor o corpus deste estudo, sobre as práticas pedagógicas, formação e desenvolvimento profissional docente do professor no Ensino Superior, identificamos, inicialmente, as palavras-chave de cada uma delas.

Sobre as palavras-chave, comungamos com Miguéis et al. (2013, p.15) quando afirmam que elas "expõem a abrangência de um assunto e os seus conceitos principais, que se podem revelar úteis para a indexação em mecanismos de pesquisa ou para a categorização do texto [...] O seu uso potencia o acesso ao conteúdo dos documentos [...]traduz o pensamento dos autores $[\ldots] "$.

O gráfico 1 mostra a frequência das palavras-chave mais citadas nos artigos selecionados. Como pode ser observado, considerando as afirmações de Miguéis et al. (2013), os assuntos e conceitos mais abrangentes dos estudos referem-se a educação superior; prática docente; ensino superior; educação; ensino; formação continuada de professores; e professor universitário. A frequência alta dessas palavras, como era de esperar, justifica-se pelos termos indutores utilizados na busca, que foram "Desenvolvimento Profissional Docente do Professor da Educação Superior"; “A Formação Continuada de Professores no Ensino Superior"; e "Práticas Pedagógicas na Educação Superior.".

Gráfico 1: Palavras-chave mais citadas nos artigos selecionados 


\section{Palavras-chaves mais citadas}

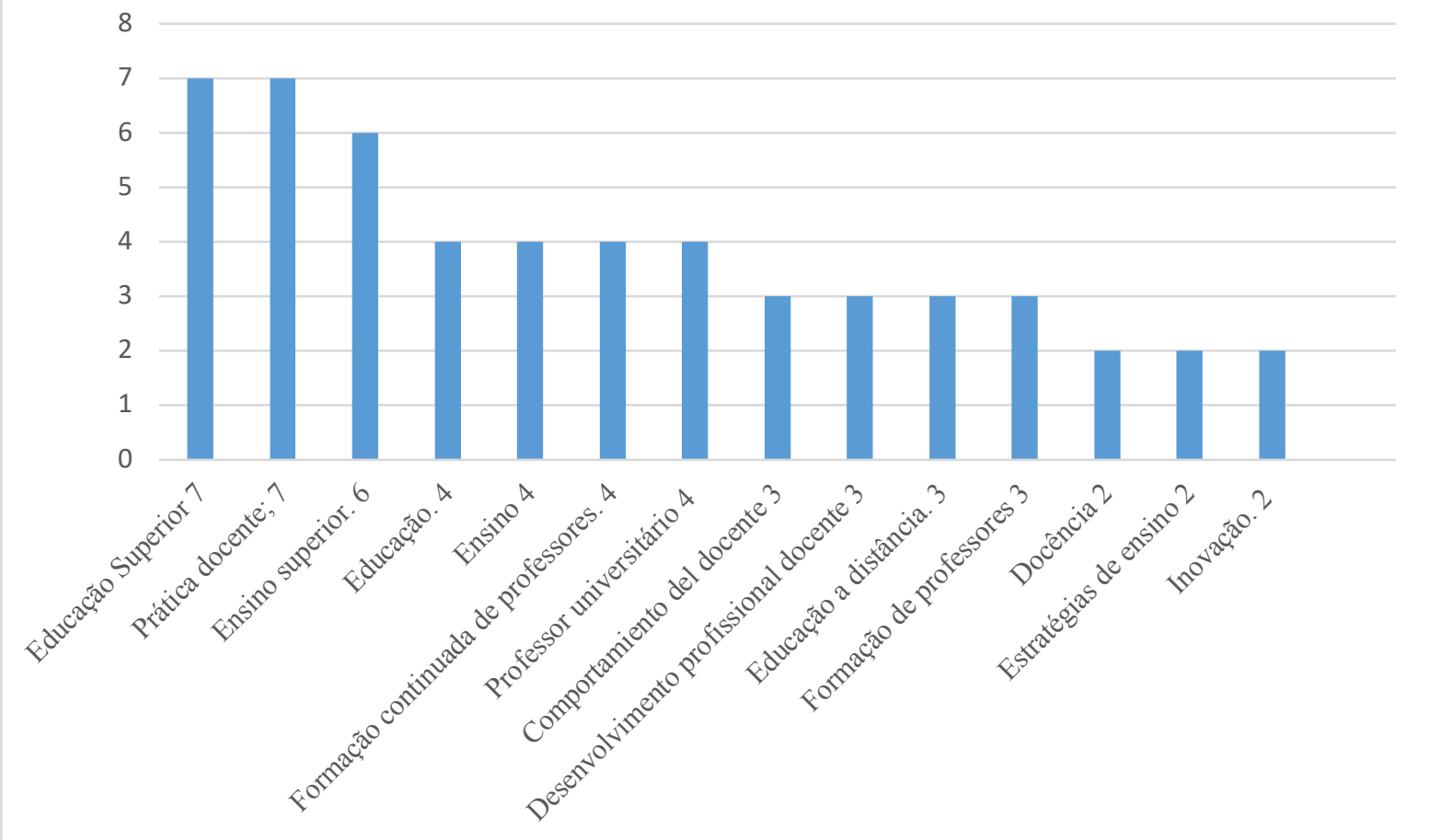

Fonte: dados da pesquisa.

\subsubsection{Problema da pesquisa, objetivos e os respectivos objetos de estudo.}

Da mesma forma que as palavras-chave, o problema e os objetivos também têm relação com os termos indutores. Isto é, dizem respeito, principalmente, à formação e ao desenvolvimento profissional do professor no ensino superior e às práticas pedagógicas desenvolvidas por eles.

O quadro 4 apresenta os problemas das pesquisas com os respectivos objetivos.

Quadro 4: Problemas das pesquisas selecionadas e seus respectivos objetivos.

\begin{tabular}{|l|l|l|}
\hline $\mathbf{N}^{\mathbf{0}}$ & Problema de pesquisa & Objetivos \\
\hline 01 & $\begin{array}{l}\text { Qual a relação entre avaliação e qualidade do } \\
\text { desenvolvimento profissional docente? }\end{array}$ & $\begin{array}{l}\text { Refletir sobre a relação existente entre } \\
\text { avaliação e qualidade profissional docente. }\end{array}$ \\
\hline 02 & $\begin{array}{l}\text { Qual a percepção dos profissionais da } \\
\text { Educação Superior Técnico Profissional } \\
\text { chilena sobre seu trabalho docente? }\end{array}$ & $\begin{array}{l}\text { Explorar y analizar las percepciones de los } \\
\text { profesionales chilenos Enseñanza Superior } \\
\text { Profesional Técnica de trabajo en la industria y } \\
\text { hacer la enseñanza como parte de su jornada }\end{array}$ \\
\hline
\end{tabular}




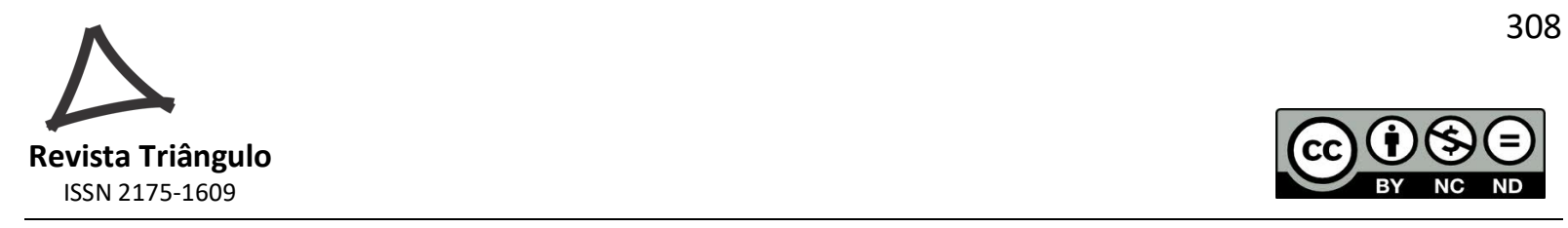

\begin{tabular}{|c|c|c|}
\hline & & laboral. \\
\hline 03 & $\begin{array}{l}\text { Como ocorreu a aprendizagem para a } \\
\text { docência no contexto do ensino superior? } \\
\text { Como os professores utilizam as suas } \\
\text { experiências docentes para a sua própria } \\
\text { constituição profissional? }\end{array}$ & $\begin{array}{l}\text { Entender como se deu a aprendizagem para a } \\
\text { docência de professores que atuam em uma } \\
\text { instituição pública brasileira de educação } \\
\text { superior. }\end{array}$ \\
\hline 04 & $\begin{array}{l}\text { Como é o início da experiência de } \\
\text { professores universitários na docência no } \\
\text { Ensino Superior? Há diferenças nessas } \\
\text { vivências iniciais entre aqueles que tiveram } \\
\text { experiências docentes anteriores à docência } \\
\text { universitária? Quais as relações entre os } \\
\text { diferentes agentes (instituição, alunos e } \\
\text { professor) presentes nesse processo? }\end{array}$ & $\begin{array}{l}\text { Analisar como docentes do Ensino Superior de } \\
\text { uma universidade pública percebem os } \\
\text { diferentes agentes do campo educacional, e } \\
\text { como as tensões e dificuldades são gerenciadas } \\
\text { no início da profissão, partindo da noção de } \\
\text { campo de Bourdieu. }\end{array}$ \\
\hline 05 & $\begin{array}{l}\text { Quais as repercussões do produtivista } \\
\text { acadêmico no desenvolvimento profissional } \\
\text { de professores universitários? }\end{array}$ & $\begin{array}{l}\text { Discutir o impacto da lógica do produtivismo } \\
\text { acadêmico no desenvolvimento profissional } \\
\text { docente a partir da compreensão do professor } \\
\text { como intelectual. }\end{array}$ \\
\hline 06 & $\begin{array}{l}\text { Quais as necessárias transformações dos } \\
\text { cursos a distância em função das ciber } \\
\text { cultura? }\end{array}$ & $\begin{array}{l}\text { Discutir a formação continuada do professor } \\
\text { universitário face à presença das tecnologias } \\
\text { digitais de informação e comunicação e à } \\
\text { explosão do uso da educação a distância no } \\
\text { país. }\end{array}$ \\
\hline 07 & $\begin{array}{l}\text { Como se configuram as necessidades } \\
\text { formativas de docentes recém-admitidos } \\
\text { numa universidade pública? }\end{array}$ & $\begin{array}{l}\text { Discutir pesquisa sobre necessidades } \\
\text { formativas de docentes universitários. }\end{array}$ \\
\hline 08 & $\begin{array}{l}\text { Que resultados podem ser observados da } \\
\text { experiência formativa do GTPA - Grupo de } \\
\text { trabalho sobre pedagogia para autonomia, } \\
\text { que busca exercitar o compartilhamento e a } \\
\text { reflexão de práticas docentes? }\end{array}$ & $\begin{array}{l}\text { Compartilhar experiências docentes, } \\
\text { estreitando a relação teoria-prática de ensino a } \\
\text { fim identificar os saberes do ensinar, as formas } \\
\text { de trabalhar em sala de aula, a intencionalidade } \\
\text { da ação e os resultados da ação planejada. }\end{array}$ \\
\hline 09 & $\begin{array}{l}\text { Que saberes docentes são mobilizados pelos } \\
\text { professores dos cursos de Licenciatura em } \\
\text { Ciências Naturais e Matemática, } \\
\text { desenvolvidos na modalidade de EAD, nos } \\
\text { Institutos Federais de Educação, Ciência e } \\
\text { Tecnologia? }\end{array}$ & $\begin{array}{l}\text { Analisar os saberes docentes mobilizados } \\
\text { pelos professores dos cursos de Licenciatura } \\
\text { em Ciências Naturais e Matemática na } \\
\text { modalidade de educação a distância (EAD) nos } \\
\text { Institutos Federais (IF) de Educação, Ciência e } \\
\text { Tecnologia. }\end{array}$ \\
\hline 10 & $\begin{array}{l}\text { Quais eventuais marcas disjuntivas podemos } \\
\text { encontrar, sobre a prática pedagógica } \\
\text { cotidiana desenvolvidas por professores/ }\end{array}$ & $\begin{array}{l}\text { Encontrar eventuais marcas distintivas na } \\
\text { docência dos professores do ensino superior da } \\
\text { área de Saúde sobre sua pratica pedagógica }\end{array}$ \\
\hline & (C) Rev. Triang. & \begin{tabular}{l|l|l|}
.11 & n.2 & p. 300-324
\end{tabular} \\
\hline
\end{tabular}




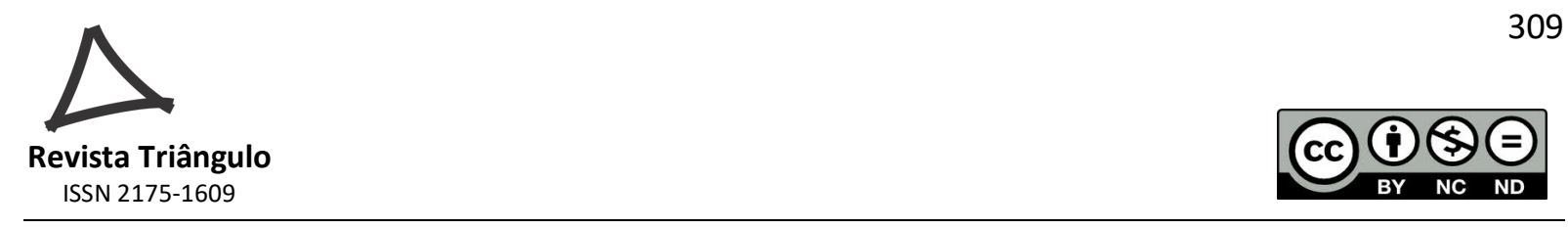

\begin{tabular}{|c|c|c|}
\hline & $\begin{array}{l}\text { coordenadores/ diretores do ensino superior } \\
\text { da área da saúde? }\end{array}$ & cotidiana. \\
\hline 11 & $\begin{array}{l}\text { Como apreender o tema Metodologia Ativa e } \\
\text { aplica-la no contexto de uma disciplina? }\end{array}$ & $\begin{array}{l}\text { Relatar as vivências no desenvolvimento do } \\
\text { tema Metodologia Ativa por meio da utilização } \\
\text { do Arco de Charles Maguerez em um } \\
\text { seminário, durante uma disciplina do Curso de } \\
\text { Mestrado em Enfermagem, de uma instituição } \\
\text { federal de ensino. }\end{array}$ \\
\hline 12 & $\begin{array}{l}\text { ¿Cuáles son las concepciones de enseñanza, } \\
\text { para el estudio de la educación universitaria } \\
\text { de medicina, respaldan las prácticas } \\
\text { pedagógicas de los profesores en el aula? }\end{array}$ & $\begin{array}{l}\text { Es estudiar las prácticas y concepciones sobre } \\
\text { la enseñanza que poseen } 25 \text { profesores } \\
\text { universitários de la carrera de medicina. }\end{array}$ \\
\hline 13 & $\begin{array}{l}\text { Quais as influências das concepções dos } \\
\text { estudantes-professores, dos professores- } \\
\text { formadores e dos programas de formação } \\
\text { (Curso de Educação Física) no planejamento } \\
\text { e na implementação das práticas } \\
\text { pedagógicas? }\end{array}$ & $\begin{array}{l}\text { Apresentar e discutir alguns critérios que } \\
\text { subsidiem os programas de formação inicial } \\
\text { em Educação Física nas tarefas de estruturação } \\
\text { e de implementação dessas práticas } \\
\text { pedagógicas. }\end{array}$ \\
\hline 14 & $\begin{array}{l}\text { What the concept understood by ESF } \\
\text { professionals in Basic Health Care Units } \\
\text { (UBS) with regard knowledge, education } \\
\text { and the subjects participating in learning } \\
\text { activities developed by them? }\end{array}$ & $\begin{array}{l}\text { To investigate the concept understood by } \\
\text { Family Healthcare Strategy (ESF) } \\
\text { professionals of knowledge, education and } \\
\text { subjects participating in learning activities. }\end{array}$ \\
\hline 15 & $\begin{array}{l}\mathrm{O} \text { que é e como funciona a Espiral } \\
\text { Construtiva no ensino? }\end{array}$ & $\begin{array}{l}\text { Apresentar e fundamentar a metodologia da } \\
\text { espiral construtivista. }\end{array}$ \\
\hline 16 & $\begin{array}{l}\text { Quais as implicações da formação } \\
\text { continuadas a partir do PNE sobre o trabalho } \\
\text { docente? }\end{array}$ & $\begin{array}{l}\text { Discutir questões relativas à formação de } \\
\text { professores, com ênfase na formação } \\
\text { continuada, a partir da análise das Metas } 15 \text { e } \\
16 \text { do Plano Nacional de Educação - PNE } \\
2014-2024 \text {. }\end{array}$ \\
\hline 17 & $\begin{array}{l}\text { Como se configura a prática pedagógica do } \\
\text { docente orientador de estágio em Saúde } \\
\text { Coletiva (SC) diante das transformações } \\
\text { sociopolíticas da sociedade brasileira e da } \\
\text { educação, no contexto da formação para o } \\
\text { SUS? }\end{array}$ & $\begin{array}{l}\text { Analisar o perfil de formação, bases da ação e } \\
\text { planejamento pedagógico do docente de } \\
\text { enfermagem orientador de estágio em Saúde } \\
\text { Coletiva de instituições de ensino superior de } \\
\text { dois municípios do centro-oeste paulista, à luz } \\
\text { das políticas públicas de educação e saúde. }\end{array}$ \\
\hline
\end{tabular}



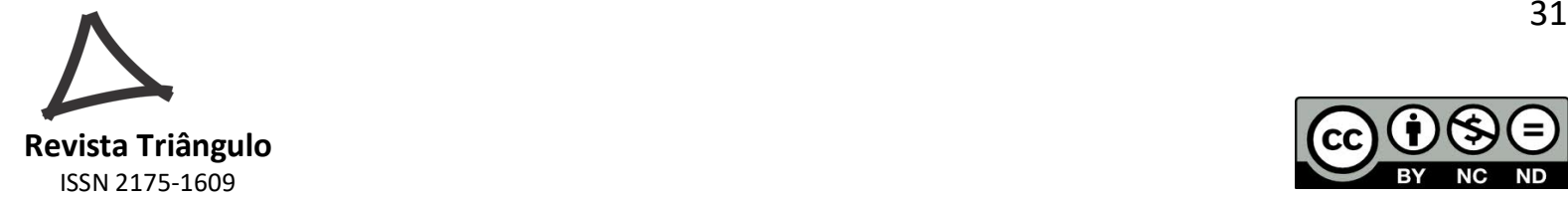

\begin{tabular}{|c|c|c|}
\hline 18 & $\begin{array}{l}\text { Em que medida os clichés nos discursos } \\
\text { sobre a educação, nos dias atuais, atingem as } \\
\text { práticas didático-pedagógicas? }\end{array}$ & $\begin{array}{l}\text { Estudar formas de integração entre a } \\
\text { convocação de usos e a proposição de novos } \\
\text { modos de existência, pela modelação de novas } \\
\text { possibilidades de uso didático-pedagógico na } \\
\text { Educação a Distância no ensino superior. }\end{array}$ \\
\hline 19 & $\begin{array}{l}\text { ¿Cuál es el significado de las prácticas } \\
\text { pedagógicas para los profesores de } \\
\text { enfermería? }\end{array}$ & $\begin{array}{l}\text { Identificar en las publicaciones de revistas } \\
\text { nacionales e internacionales indexadas en las } \\
\text { bases de datos Lilacs, Cihnal, Medline, Scielo, } \\
\text { Wilson, Bdenf en el período } 2005-2009 \text { los } \\
\text { datos relacionados con el significado de la } \\
\text { práctica pedagógica de los profesores de } \\
\text { enfermería. }\end{array}$ \\
\hline 20 & $\begin{array}{l}\text { Como os conhecimentos sobre a sala de aula, } \\
\text { a escola e a comunidade incidem na } \\
\text { construção do Conhecimento pedagógico do } \\
\text { Conteúdo (CPC) dos futuros professores e } \\
\text { nos cursos de formação inicial em Educação } \\
\text { Física }\end{array}$ & $\begin{array}{l}\text { Analisar como os conhecimentos sobre a sala } \\
\text { de aula (microcontexto), a escola } \\
\text { (mesocontexto) e a comunidade } \\
\text { (macrocontexto) incidem na construção do } \\
\text { CPC dos futuros professores e nos cursos de } \\
\text { formação inicial em Educação Física. }\end{array}$ \\
\hline 21 & $\begin{array}{l}\text { What are the conceptions of pedagogical } \\
\text { training for university teachers? }\end{array}$ & $\begin{array}{l}\text { To examine the pedagogical training process } \\
\text { of medical professors in a Brazilian university, } \\
\text { the meanings that are attributed and the } \\
\text { positive and negative aspects identified in it. }\end{array}$ \\
\hline 22 & $\begin{array}{l}\text { O que mostram as principais publicações } \\
\text { nacionais e internacionais sobre o tema } \\
\text { "ensino de empreendedorismo" em cursos de } \\
\text { Graduação e Pós graduação? }\end{array}$ & $\begin{array}{l}\text { Realizar um estado-da-arte de práticas } \\
\text { didático-pedagógicas utilizadas no ensino de } \\
\text { empreendedorismo nos cursos de graduação e } \\
\text { pós-graduação nacionais e estrangeiros. }\end{array}$ \\
\hline 23 & $\begin{array}{l}\text { Quais são as práticas pedagógicas } \\
\text { desenvolvidas pelos professores no ensino } \\
\text { de enfermagem? Elas promovem mudanças e } \\
\text { inovações pedagógicas? }\end{array}$ & $\begin{array}{l}\text { Conhecer as práticas pedagógicas que já vêm } \\
\text { sendo desenvolvidas no ensino de } \\
\text { Enfermagem, para identificar e analisar } \\
\text { aquelas que promoveram mudanças e } \\
\text { inovações pedagógicas }\end{array}$ \\
\hline 24 & $\begin{array}{l}\text { Como incrementar a pesquisa na graduação } \\
\text { de maneira ampliada, e ainda considerar a } \\
\text { unidade ser humano, profissional e cidadão? }\end{array}$ & $\begin{array}{l}\text { Analisar a sistematização de práticas } \\
\text { pedagógicas de ensinar-aprender pesquisa no } \\
\text { cotidiano das disciplinas de um curso de } \\
\text { graduação da área da saúde }\end{array}$ \\
\hline 25 & $\begin{array}{l}\text { O que mostram as reflexões sobre as práticas } \\
\text { pedagógicas consideradas significativas } \\
\text { pelos estudantes do Curso de Nutrição? }\end{array}$ & $\begin{array}{l}\text { Investigar as práticas pedagógicas } \\
\text { consideradas significativas pelos estudantes do } \\
\text { Curso de Nutrição. }\end{array}$ \\
\hline
\end{tabular}

Fonte: dados da pesquisa 
Para Gil (2010, p. 7), o problema de pesquisa se caracteriza por ser um "assunto controverso, ainda não satisfatoriamente respondido em qualquer campo do conhecimento [...]". Acresce ainda que um problema de pesquisa pode ser considerado de natureza científica quando "envolve proposições que podem ser testadas mediante verificação empírica" (p. 8). Para esse autor, são inúmeras as razões de ordem intelectual que auxiliam a formulação de um problema de pesquisa. Dentre elas, pode-se optar por problemas cujas respostas: sejam importantes para o subsídio de uma determinada ação; sejam voltados para avaliação de certas ações ou programas; são decorrentes de interesses práticos com vistas a planejamento de ações adequadas; demonstrem interesse na exploração de um objeto pouco conhecido; ou possibilitam testar uma teoria específica.

Ora, o problema, como afirma Gil (2010), é uma questão ainda não resolvida. É algo que busca uma resposta, e, para isso, formulam-se objetivos no sentido de definir o que será realizado para responder ao problema enunciado. Isto pode ser observado no quadro 4. Os problemas das pesquisas selecionadas, neste estudo, buscam respostas a partir dos respectivos objetivos, que dizem respeito ao desenvolvimento profissional docente e às práticas pedagógicas de professores do ensino superior.

De modo geral, é possível verificar que a maioria das pesquisas se preocupa com as práticas pedagógicas dos professores do Ensino Superior. Os objetos de estudos reforçam esta observação, como pode ser observado na figura 1. A formação e o desenvolvimento profissional docente do professor do Ensino Superior têm sido acatado como objeto de estudo, principalmente com relação às práticas pedagógicas desenvolvidas pelos professores. Das 25 pesquisas, 14 delas tratam de práticas pedagógicas, - 10 discutem as práticas pedagógicas de modo geral, e 4 abordam metodologias ou procedimentos de ensino.

Figura 1: Objetos de estudos 


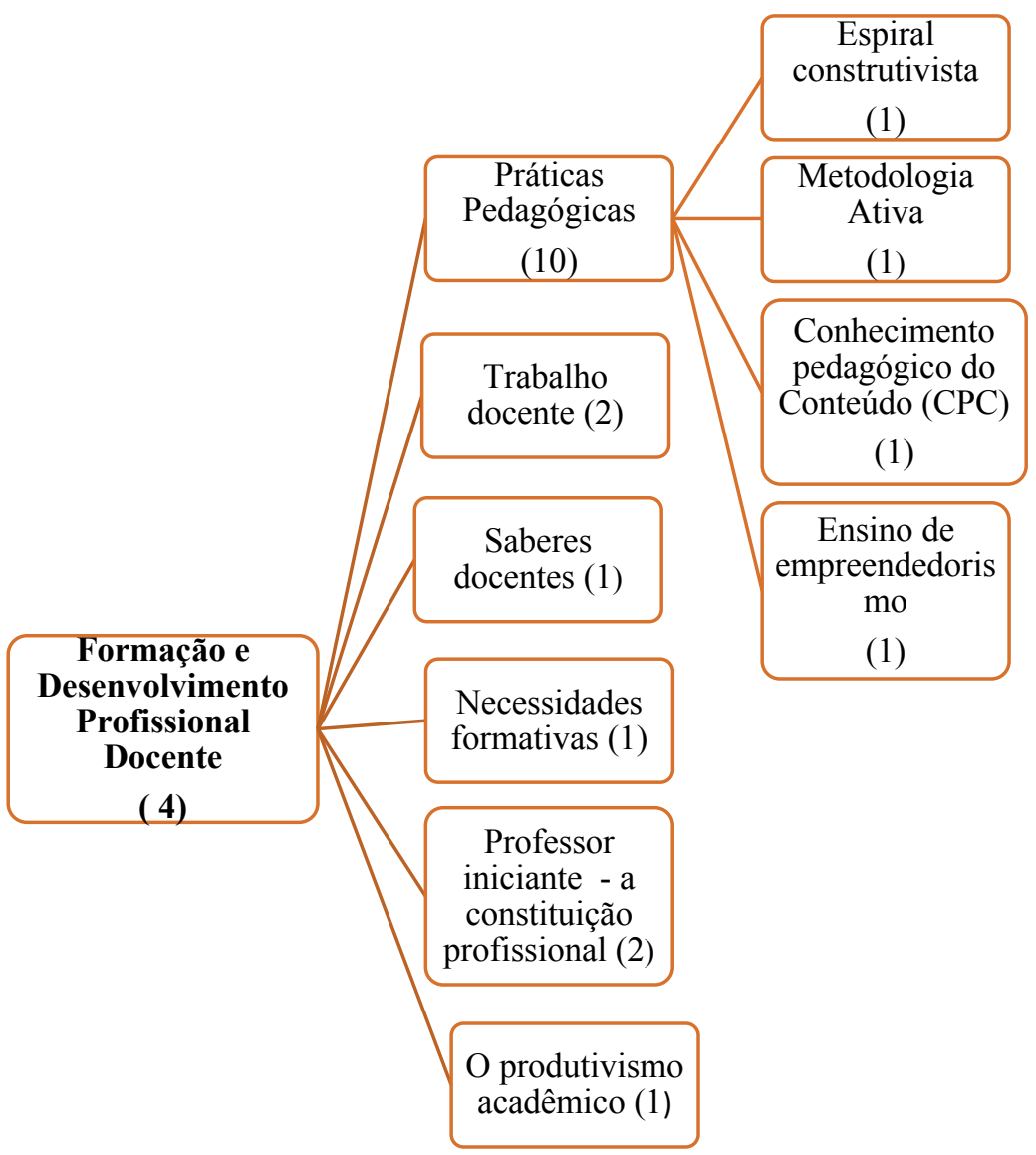

Fonte: dados da pesquisa.

Passaremos, a seguir, à análise dos resultados dessas pesquisas. Interessa-nos não só verificar o que dizem as pesquisas sobre formação e desenvolvimento profissional do professor no Ensino Superior, como também observar se esses estudos apontam resultados que evidenciam dificuldades ou fragilidades formativas dos professores.

\subsubsection{Resultados apresentados: uma análise a partir do software IRAMUTEQ}

Após leituras e estudos de cada pesquisa, identificamos os resultados e construímos um texto síntese sobre eles. Este texto foi processado no software IRAMUTEQ, como o objetivo de auxiliar a compreensão destes resultados.

O software IRAMUTEQ (Interface de $R$ pour les Analyses Multidimensionnelles de Textes et de Questionnaires) foi desenvolvido por Pierre Ratinaud (2009). "Trata-se de um programa que ancora no software $\mathrm{R}^{\mathrm{ii}}$ e permite diferentes formas de análises estatísticas sobre corpus textuais e sobre tabelas de indivíduos por palavras" (CAMARGO e JUSTO, 2013, p. 513). 


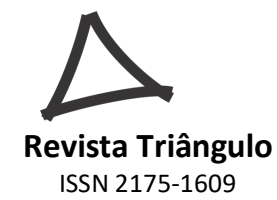

Neste estudo utilizamos a Nuvem de Palavras e a Análise de Similitude. A primeira, o software, "agrupa as palavras e as organiza graficamente em função da sua frequência. É uma análise lexical mais simples, porém graficamente interessante, na medida em que possibilita rápida identificação das palavras chave de um corpus". (CAMARGO e JUSTO, 2013, p. 516). A segunda, a Análise de Similitude, auxilia na identificação da estrutura da representação das palavras a partir da identificação das coocorrências entre elas. Baseia-se na teoria dos grafos. Essa teoria estuda a relação entre indivíduos dentro de uma rede, através de estruturas denominadas grafos. Sintetizando, a Análise de Similitude possibilita a identificação das ocorrências entre as palavras e seu resultado nas indicações da conexidade entre elas.

\subsubsection{Nuvem de Palavras}

O processamento do texto síntese no software IRAMUTEQ, sobre os resultados das 25 pesquisas selecionadas, obteve um corpus para análise de 3.738 palavras. Após a eliminação de palavras que não possuíam significado, como advérbios, conjunções, preposições e pronomes, o número de formas identificadas foi de 896 palavras. Destas, 492 com frequência igual a 1. Isto é, as palavras com frequência 1 (hápax) correspondem a 13,16\% do total de palavras do corpus e a $54,91 \%$ do número de formas identificadas, como pode ser observado no quadro 5:

Quadro 05: Resultado do processamento do corpus no software IRAMUTEQ

\begin{tabular}{|l|l|}
\hline Número de textos: & 01 \\
\hline Número de ocorrências: & 3738 \\
\hline Número de formas identificadas: & 896 \\
\hline Número Hapax: & $492(13,16 \%$ das ocorrências - 54,91\% das formas $)$ \\
\hline Ocorrência por texto: & 3738.00 \\
\hline
\end{tabular}

Fonte: software IRAMUTEQ

Dentre as 404 palavras com frequência acima de 1, destacam-se as mais incidentes. São estas que nos interessam na análise da Nuvem de Palavras:

Quadro 06: Palavras com maior número de incidências na Nuvem de Palavras

\begin{tabular}{|l|c|l|r|l|l|l|l|l|l|}
\hline \multicolumn{7}{|c|}{ Palavras e Incidências } \\
\hline professor & $\mathbf{5 4}$ & Conhecimento & 15 & aprendizagem & 9 & Objetivo & 7 & ensinar & 6 \\
\hline prático & $\mathbf{4 4}$ & Curso & 15 & universitário & 9 & Futuro & 7 & técnica & 6 \\
\hline
\end{tabular}

\begin{tabular}{|l|l|l|}
\hline v.11 & n.2 & p. 300-324
\end{tabular}



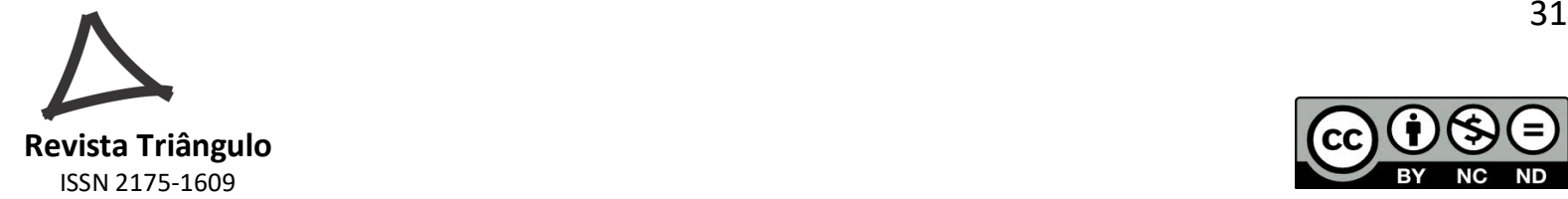

\begin{tabular}{|l|l|l|l|l|l|l|l|l|l|}
\hline formação & $\mathbf{4 1}$ & Aluno & 14 & atividade & 8 & analisar & 7 & observar & 6 \\
\hline pedagógico & $\mathbf{3 9}$ & docência & 14 & metodologia & 8 & instituição & 7 & modalidade & 6 \\
\hline docente & 31 & processo & 13 & aprender & 8 & planejamento & 7 & didático & 6 \\
\hline ensino & 28 & experiência & 11 & saúde & 8 & problema & 6 & área & 6 \\
\hline profissional & 20 & Ação & 10 & necessidade & 8 & continuar & 6 & graduação & 6 \\
\hline resultado & 20 & superior & 10 & conteúdo & 7 & condição & 6 & saber & 6 \\
\hline educação & 20 & Inicial & 10 & análise & 7 & reflexão & 6 & teórico & 6 \\
\hline pesquisa & 18 & relação & 9 & físico & 7 & formativo & 6 & distância & 6 \\
\hline estudo & 16 & desenvolvimento & 9 & identificar & 7 & contexto & 6 & enfermagem & 6 \\
\hline
\end{tabular}

Fonte: software IRAMUTEQ

Figura 02: Nuvem de Palavras

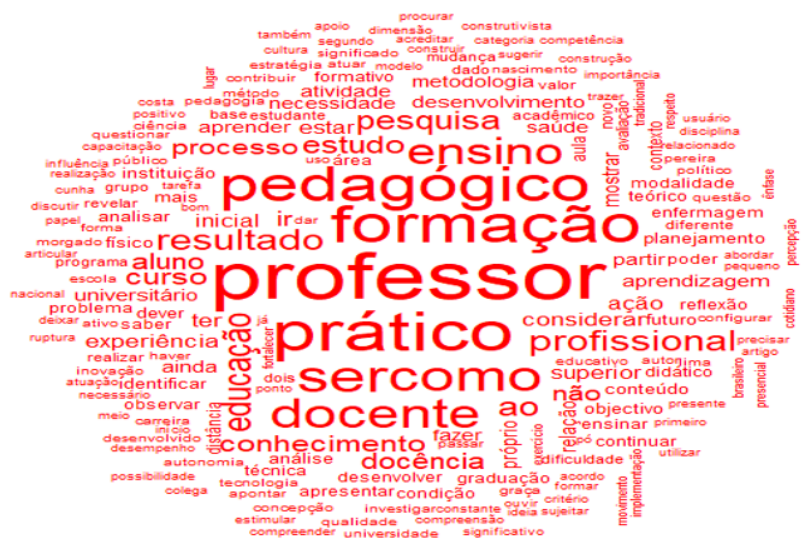

Fonte: IRAMUTQ

As palavras professor (54), prático (44), formação (41) e pedagógico (39) foram as mais mencionadas na síntese dos resultados das pesquisas. Remetendo ao texto, é possível analisar o sentido e significado dessas palavras.

A palavra "professor", a mais mencionada, diz respeito, principalmente, a questões ligadas a formação e práticas pedagógicas. Ela está inserida em contextos que evidenciam:

- Necessidade de repensar, ressignificar e mudar a formação pedagógica dos professores que atuam no ensino universitário - evitar que os professores se formem com os mesmos métodos. (MORGADO, 2014). 
- Ênfase na experiência da docência online como parte da necessária imersão no universo de ciber cultura. (PRETTO e RICCIO, 2010).

- Ausência de políticas educativas que considerarem a multiplicidade de saberes necessários para uma boa atuação do professor universitário. (VOSGERAU; ORLANDO; MEYER, 2017).

- Reflexão sobre "como" e "por que" da ação docente, que faz com que o professor compreenda a própria docência. (STANO, 2015).

- Necessidade de articular prática-teoria-prática, pois o professor têm ideia sobre um bom ensino, mas falta-lhe conhecimento específico e sistemático. (STANO, 2015).

- O papel da Pedagogia para a Autonomia na formação continuada de professores como subsídios à qualidade política de sua ação - professores aprendendo com professores e se formando continuamente num grupo (des)hierarquizado a partir da reflexão de suas práticas. (STANO, 2015).

- Professor marcante é aquele em que o profissional e o humano estiveram irremediavelmente entrelaçados. (CASTANHO, 2002).

- O alcance dos objetivos das práticas pedagógicas nos programas de formação inicial depende das concepções que os programas, os professores-formadores e os estudantesprofessores têm a respeito da participação dessas estratégias formativas na formação dos futuros professores. (MARCO, GRAÇA, E NASCIMENTO, 2011).

- O trabalho docente deva favorecer a autonomia do professor para a realização de suas práticas pedagógicas, voltadas para o desenvolvimento intelectual, cultural e científico. (MAGALHÃES e AZEVEDO, 2015).

- O significado de práticas pedagógicas mostra despreparo para ser professor. (SEBOLD e CARRARO, 2011).

- O mundo globalizado exige dos professores a articulação de diversas competências as quais articulam a prática. (SEBOLD e CARRARO, 2011).

- Sugestões de ações educativas conscientes que auxiliem o professor "no desenvolvimento de suas potencialidades, na capacidade de criar soluções e respostas adequadas, em sua condição básica de agir, conjugando crenças, valores e conhecimentos”. (COSTA, 2010, p. 7).

- As trajetórias pessoais e profissionais como fatores definidores dos modos de atuação das professoras revelam suas concepções sobre seu fazer pedagógico e indicam condições

\begin{tabular}{|l|l|l|}
\hline v.11 & n.2 & p. 300-324
\end{tabular}


presentes na constituição da profissionalidade do docente da educação superior. (PEDROSA e CUNHA, 2008).

A palavra "prático", a segunda mais mencionada, está ligada diretamente com a expressão "práticas pedagógicas e/ou docentes". Dentro do contexto dos resultados das pesquisas, a palavra "prático", pode assim ser compreendida:

- As práticas pedagógicas e/ou comunicacionais devem ser estruturadas a partir da compreensão das tecnologias digitais em rede. (PRETTO e RICCIO (2010).

- Ter um lugar para compartilhar práticas docentes apresenta-se como uma possibilidade de efetuar o salto qualitativo entre o que se faz e o que se deve fazer, a partir da reflexão, no exercício da docência. (STANO, 2015).

- A prática pedagógica precisa levar em conta as potencialidades dos alunos, contribuindo para a formação de profissionais mais bem qualificados e mais humanos. (PRADO et al (2012).

- As atividades docentes ancoram em práticas pedagógicas que privilegiam a exposição oral e reprodução de técnicas como também na desarticulação entre teoria e prática e no isolamento do trabalho docente. (DAMIANCE et al, 2016).

- A atividade de ensinar e a qualificação da prática pedagógica passam indelevelmente pelo desejo do sujeito que ensina. (PEREIRA e TAVARES, 2010).

- O ensino por meio da pesquisa como uma prática pedagógica gera desafios constantes para o professor, o que lhe possibilita maior empoderamento como educador, pesquisador, e profissional de sua área. (PATRÍCIO et al, 2011).

- Para os alunos, as práticas pedagógicas significativas são as que incluem emoção, sensibilidade e percepção estética de modo que haja uma articulação entre subjetividade e objetividade. (PEDROSA e CUNHA, 2008).

A palavra "formação", terceira mais citada, encontra-se nos resultados das pesquisas, dentro de um contexto que diz respeito, principalmente, à formação continuada do professor do ensino superior, como pode ser visto nos exemplos seguintes:

- A realização de formação continuada, a partir da identificação das necessidades formativas dos professores, em contraposição à ideia de pacote pré-elaborado, mostra os seguintes resultados: a) dificuldades nas condições estruturais da instituição; b) dificuldades com relação ao planejamento, conteúdo e avaliação; c) sugerem para a formação continuada o estudo de questões ligadas ao planejamento e metodologias de ensino como formas

\begin{tabular}{|l|l|l|l|}
\hline v.11 & n.2
\end{tabular}


específicas do trabalho pedagógico, como o trabalho de campo, trabalho com projetos e outros. (LIMA, 2015).

- A formação continuada é condição necessária no processo de formação ao longo da carreira, mas não suficiente para o pleno exercício da docência. É preciso que o trabalho docente favoreça a autonomia do professor para a realização de suas práticas pedagógicas. (MAGALHÃES e AZEVEDO, 2015).

- A formação continuada de professores pode auxiliar na atualização de métodos pedagógicos e a ampliação da compreensão da área educativa. (COSTA, 2010).

A palavra "pedagógico", a quarta mais mencionada, traz diferentes significados no contexto dos resultados das pesquisas. Ora se apresenta como trabalho pedagógico, ora como referencial teórico-pedagógico e outros, como: conhecimento pedagógico, planejamento pedagógico, didático-pedagógico, o fazer pedagógico e métodos pedagógicos. Podem-se destacar os seguintes resultados:

- Necessidade de estudar o tema "trabalho pedagógico" na formação continuada. (LIMA, 2015).

- É preciso pensar a prática a partir de determinado referencial teórico-pedagógico. (STANO, 2015).

- A implementação de diferentes modalidades de práticas pedagógicas potencializa o próprio conhecimento pedagógico do conteúdo. (MARCO, GRAÇA, E NASCIMENTO, 2011).

- No discurso dito moderno, os sujeitos reconfiguram o fazer pedagógico a partir de uma euforização de valores como flexibilidade, informalidade, ludicidade e imediatismo. (PEREIRA e CESAR, 2016).

Desses resultados emergem algumas dificuldades e/ou fragilidades formativas que podem ser entendidas como necessidades formativas. É o que mostra o quadro 07:

Quadro 07: Dificuldades ou fragilidades dos professores

\begin{tabular}{|l|l|}
\hline Palavra & Dificuldades ou fragilidades \\
\hline Professor & • Imergir no universo de ciber cultura. \\
& - Conhecer os saberes necessários para uma boa atuação do professor universitário. \\
& - Apropriar-se de conhecimento específico e sistemático na articulação da prática- \\
& - Preoria-prática. \\
& - Saber articular as práticas pedagógicas com mundo globalizado. \\
\hline
\end{tabular}




\section{$\Delta$ \\ Revista Triângulo \\ ISSN 2175-1609}

\begin{tabular}{|c|c|}
\hline $\begin{array}{l}\text { Prático } \\
\text { (Práticas } \\
\text { pedagógicas) }\end{array}$ & $\begin{array}{l}\text { - Estruturar as práticas pedagógicas a partir das tecnologias digitais. } \\
\text { - Considerar as potencialidades dos alunos na escolha e realização das práticas } \\
\text { pedagógicas. } \\
\text { - Compreender que práticas pedagógicas, que privilegiam a exposição oral e } \\
\text { - } \text { reprodução de técnicas, dificultam a articulação entre teoria e prática. } \\
\text { - da sua prática pedagógica. } \\
\text { - Reconhecer que práticas pedagógicas significativas para os alunos são que } \\
\text { incluem emoçãao, sensibilidade e percepção estética a partir de uma articulação } \\
\text { entre subjetividade e objetividade. }\end{array}$ \\
\hline Formação & $\begin{array}{l}\text { - Realizar planejamento, escolher conteúdos e avaliar. } \\
\text { - Ter autonomia no trabalho docente para a realização das práticas pedagógicas. } \\
\text { - } \quad \text { Atualizar as metodologias de ensino. }\end{array}$ \\
\hline Pedagógico & $\begin{array}{l}\text { - } \quad \text { Compreender melhor o trabalho pedagógico. } \\
\text { - Estudar um referencial teórico-pedagógico para pensar a prática. } \\
\text { - Potencializar o próprio conhecimento pedagógico a partir da implementação de } \\
\text { diferentes práticas pedagógicas. } \\
\text { - Compreender o fazer pedagógico no discurso dito moderno. }\end{array}$ \\
\hline
\end{tabular}

Fonte: dados da pesquisa

\subsubsection{Análise de Similitude}

Como dito anteriormente, a análise de similitude "possibilita identificar as coocorrências entre as palavras e seu resultado traz indicações da conexidade entre as palavras, auxiliando na identificação da estrutura de um corpus textual". (CAMARGO; JUSTO, 2013, p 516). Isto é, a imagem gerada pelo software mostra a ramificação das palavras organizadas de acordo com suas ligações dentro de um texto. Quanto mais representatividade tiver a palavra, maior ela será. Os ramos que ligam as palavras demostram, na sua maior ou menor largura, a similitude e correlação que existem entre elas. Portanto, a partir dessa análise, é possível compreender, de acordo com sua importância, a estrutura de construção de um texto e temas. Assim, buscamos nessa análise, identificar e compreender os resultados das 25 pesquisas selecionadas para este estudo.

Como mostra a figura 03, podemos identificar a ocorrência entre as palavras mais mencionadas no texto e as indicações da conexidade entre elas. Constata-se a presença de quatro blocos de palavras com um alto grau de conexidade entre elas: "professor", "prático", "formação" e "pedagógico". A coocorrência entre elas é possível observar por meio da largura das linhas de ligação com outras destacadas. Em menor grau de aglutinação, constatase a presença das palavras: “docente”, "ensino", "profissional” e "educação".

Figura 03: Análise de similitude 


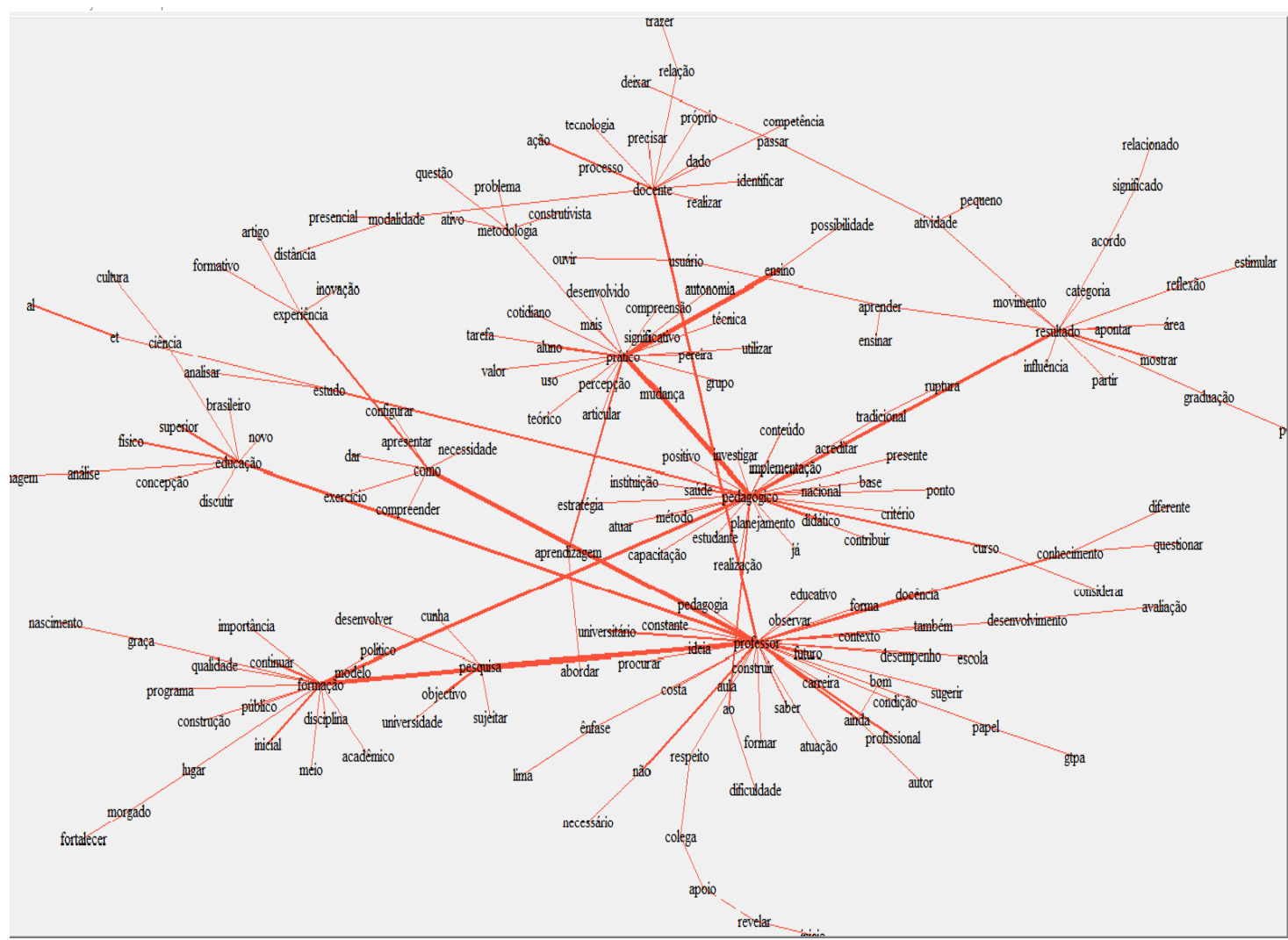

Fonte: IRAMUTQ

Diante de uma análise geral da figura, pode-se considerar, por meio das conexões instaladas, que as pesquisas estudadas mostram resultados que evidenciam uma forte ligação entre as palavras mais mencionadas: "professor", "prático", "formação" e "pedagógico". Essas palavras encontram-se em destaque, possibilitando inferir que elas representam as palavras aglutinadoras das demais, no conjunto do texto síntese dos resultados apresentados pelas pesquisas, ou seja, apresentam forte conexidade entre elas e as demais interligadas.

Assim, pesquisas que tratam dos temas: Desenvolvimento Profissional Docente do Professor da Educação Superior; A Formação Continuada de Professores no Ensino Superior; e Práticas Pedagógicas na Educação Superior, mostram resultados que possibilitam algumas inferências, a saber:

A palavras "Professor", a mais citada, encontra-se no centro da discussão, e esta, por sua vez, fortemente relacionada com "prática", "formação" e "pedagógico". No bloco representado por ela aparece uma grande concentração de palavras relacionadas com: formação, pesquisa, estudo, conhecimento, necessário, docência, desempenho, profissional, carreira, escola, aula e universitário. 
Retornando ao contexto do texto original, ou seja, da síntese dos resultados das pesquisas, é possível verificar o sentido e o significado dessas palavras, agora relacionadas entre si. Pode-se observar que o conjunto dessas palavras se refere à figura do professor universitário que necessita, para construir uma carreira profissional e ter um bom desempenho nas aulas que ministra, uma formação contínua de qualidade, realizada a partir de estudos e pesquisas que propiciem conhecimentos sobre as práticas pedagógicas que serão desenvolvidas por ele.

Essas práticas pedagógicas estão representadas na figura, pelos blocos "prático" e "pedagógico". O conjunto das palavras que constituem esses blocos são: ensino, aprendizagem, pedagógico, planejamento, conteúdo, didático, método, estratégia, tradicional, ruptura e implementar. No contexto do texto original, essas palavras referem-se a resultados de pesquisas que mostram a necessidade de uma formação continuada para os professores do Ensino Superior, que lhes deem subsídios para compreender e desenvolver suas práticas pedagógicas. Os resultados sugerem uma ruptura com métodos tradicionais e a implementação de práticas que possam favorecer o ensino e a aprendizagem dos alunos. Essas afirmações podem ser verificadas, principalmente, nas pesquisas de Lima (2015); Sebold e Carraro (2011); Marco, Graça, e Nascimento (2011); Damiance et al. (2016), respectivamente, quando mostram que: há necessidade de incluir na formação continuada de professores do Ensino Superior o estudo de questões ligadas ao planejamento e metodologias de ensino como formas específicas do trabalho pedagógico; o significado de práticas pedagógicas mostra despreparo para ser professor, e o mundo globalizado exige a articulação de diversas competências as quais articulam a prática; a implementação de diferentes modalidades de práticas pedagógicas potencializa o próprio conhecimento pedagógico do conteúdo; as práticas pedagógicas privilegiam a exposição oral e reprodução de técnicas e, consequentemente, a desarticulação entre teoria e prática.

\section{CONSIDERAÇÕES FINAIS}

Para tecer algumas considerações, retomamos aqui as questões norteadoras deste estudo, apontadas no início deste texto.

Sobre o que dizem as pesquisas acerca do objeto de estudo, pode-se inferir que as palavras-chave com maior frequência, traduzem os conceitos mais abrangentes dos estudos.

\begin{tabular}{|l|l|l|l}
\hline v.11 & n.2
\end{tabular}


São elas: educação superior; prática docente; ensino superior; educação; ensino; formação continuada de professores; e professor universitário.

Quanto à formação e o desenvolvimento profissional do docente no Ensino Superior influenciarem as práticas pedagógicas desenvolvidas por eles, percebe-se um consenso dessas influências entre as pesquisas, principalmente quando evidenciam que ter um "lugar para compartilhar práticas docentes, apresenta-se como uma possibilidade de efetuar o salto qualitativo entre o que se faz e o que se deve fazer, a partir da reflexão, no exercício da docência”. (STANO, 2015, p. 288).

Com relação às dificuldades ou fragilidades formativas dos professores, foi possível identificar nas pesquisas também um consenso entre elas. A maioria diz respeito a dificuldades ou fragilidade quanto à compreensão e desenvolvimento das práticas pedagógicas no Ensino Superior.

Vale ressaltar que este estudo não só permitiu conhecer o que se tem produzido na academia sobre a "Formação e Desenvolvimento Profissional Docente e Práticas Pedagógicas do Professor da Educação Superior”, objeto de estudo de uma pesquisa maior, como também contribuiu para subsidio teórico e metodológico no desenvolvimento desta pesquisa maior.

\section{REFERÊNCIAS}

CAMARGO, Brigido Vizeu; JUSTO, Ana Maria. IRAMUTEQ: um software gratuito para análises de dados textuais. Temas psicol, Ribeirão Preto, v. 21, n. 2, p. 513-518, dez. 2013.

CASTANHO, Maria Eugênia. Professores de Ensino Superior da área da Saúde e sua prática pedagógica. Interface (Botucatu), Botucatu, v. 6, n. 10, p. 51-61, Feb. 2002.

COSTA, Nilce Maria da Silva Campos. Pedagogical training of medicine professors. Rev. Latino-Am. Enfermagem, Ribeirão Preto, v. 18, n. 1, p. 102-108, Feb. 2010 .

DAMIANCE, Patrícia Ribeiro Mattar et al . Formação para o sus: uma análise sobre as concepções e práticas pedagógicas em saúde coletiva. Trab. educ. saúde, Rio de Janeiro, v. 14, n. 3, p. 699-721, Dec. 2016.

DELGADO, Carolina Barrientos, GÁMEZ, Antonio Navío. Formador de la educación superior técnico profesional: Percepciones sobre su trabajo docente.

Estudios Pedagógicos XLI, N 1: 45-61, 2015.

FERREIRA, N. S. A. As pesquisas denominadas "estado da arte". Educação \& Sociedade, São Paulo, ano 23, n. 79, p. 257-272, ago. 2002. 

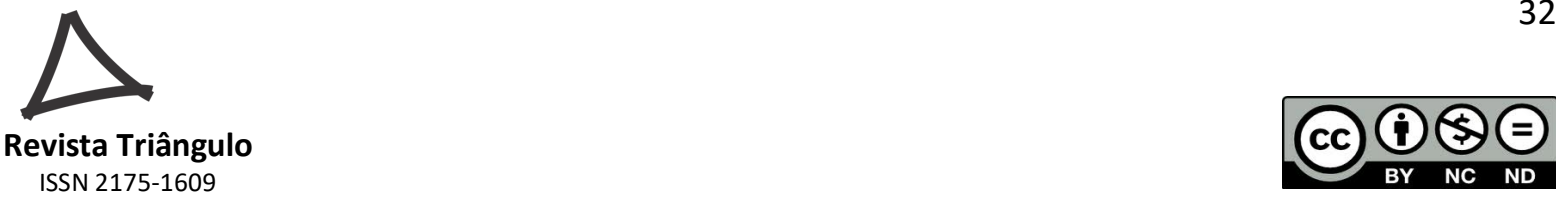

FREIRE, Leila Inês Follmann; FERNANDEZ, Carmen. O professor universitário novato: tensões, dilemas e aprendizados no início da carreira docente. Ciênc. Educ., Bauru, v. 21, n. 1, p. 255-272, 2015.

GAZZINELLI, Maria Flavia et al. Educational Group Practices in Primary Care: Interaction Between Professionals, Users and Knowledge. Rev. esc. enferm. USP, São Paulo, v. 49, n. 2, p. 0284-0291, Apr. 2015.

GIL, A. C. Como elaborar projetos de pesquisa. 5. Ed. São Paulo: Atlas, 2010.

HENRIQUE, Daniel Christian; CUNHA, Sieglinde Kindl da. Práticas didático-pedagógicas no ensino de empreendedorismo em cursos de graduação e pós-graduação nacionais e internacionais. RAM, Rev. Adm. Mackenzie, São Paulo, v. 9, n. 5, p. 112-136, 2008.

LIMA, Emília Freitas de. Análise de necessidades formativas de docentes ingressantes numa universidade pública. Rev. Bras. Estud. Pedagog., Brasília, v. 96, n. 243, p. 343-358, Aug. 2015.

LIMA, Valéria Vernaschi. Espiral construtivista: uma metodologia ativa de ensinoaprendizagem. Interface (Botucatu), Botucatu, v. 21, n. 61, p. 421-434, June 2017.

MAGALHÃES, Lígia Karam Corrêa de; AZEVEDO, Leny Cristina Soares Souza. Formação continuada e suas implicações: entre a lei e o trabalho docente. Cad. Cedes, Campinas, v. 35, n. 95, p. 15-36, jan.-abr., 2015.

MARCON, Daniel; GRACA, Amândio Braga dos Santos; NASCIMENTO, Juarez Vieira do. Critérios para a implementação de práticas pedagógicas na formação inicial em educação física e implicações no conhecimento pedagógico do conteúdo dos futuros professores. Rev. bras. educ. fís. esporte (Impr.), São Paulo, v. 25, n. 3, p. 497-511, Sept. 2011.

MARCON, Daniel; GRACA, Amândio Braga dos Santos; NASCIMENTO, Juarez Vieira do. O conhecimento do contexto na formação inicial em Educação Física. Rev. bras. educ. fís. esporte, São Paulo, v. 27, n. 4, p. 633-645, Dec. 2013.

MIGUÉIS, A; et al. A. A importância das palavras-chave dos artigos científicos da área das Ciências Farmacêuticas, depositados no Estudo Geral: estudo comparativo com os termos atribuídos na MEDLINE. InCID: R. Ci. Inf. e Doc., Ribeirão Preto, v. 4, n. 2, Ed. esp., p. $112-$ 125, jul./dez. 2013.

MORGADO, José Carlos. Avaliação e qualidade do desenvolvimento profissional docente: que relação? Avaliação, Campinas; Sorocaba, SP, v. 19, n. 2, p. 345-361, jul. 2014;

MOROSINIA, M. C; FERNANDES, C. M. B. Estado do Conhecimento: conceitos, finalidades e interlocuções. Educação Por Escrito, Porto Alegre, v. 5, n. 2, p. 154-164, jul.dez. 2014. 

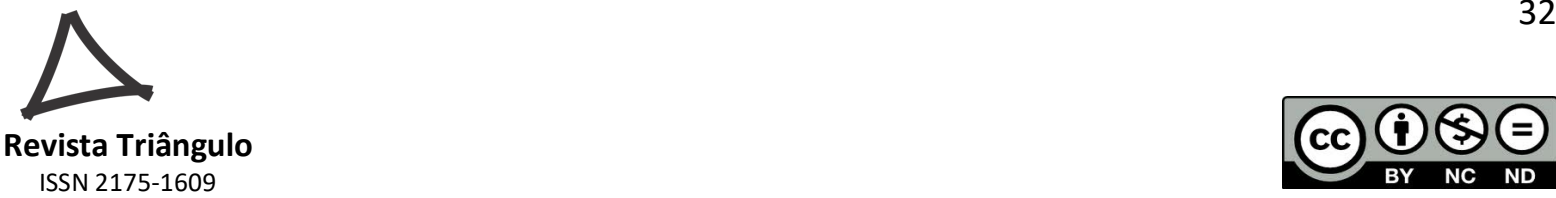

PASQUALLI, Roberta; CARVALHO, Marie Jane Soares. Os saberes docentes nos cursos de licenciatura a distância em ciências naturais e matemática nos institutos federais do Brasil.

Ciênc. Educ., Bauru, v. 22, n. 2, p. 523-540, 2016.

PATRICIO, Zuleica Maria et al . Sistematização de estratégias de ensinar-aprender pesquisa na graduação. Interface (Botucatu), Botucatu , v. 15, n. 39, p. 1159-1172, Dec. 2011.

PEDROSO, Maísa Beltrame; CUNHA, Maria Isabel da. Vivendo a inovação: as experiências no curso de nutrição. Interface (Botucatu), Botucatu , v. 12, n. 24, p. 141-152, Mar. 2008.

PEREIRA, Daniervelin Renata Marques; CESAR, Danilo Rodrigues. Inovação e abertura no discurso das práticas pedagógicas. Avaliação (Campinas), Sorocaba , v. 21, n. 2, p. 619 636, July 2016

PEREIRA, Wilza Rocha; TAVARES, Cláudia Mara Melo. Práticas pedagógicas no ensino de enfermagem: um estudo na perspectiva da análise institucional. Rev Esc Enferm USP 2010. Disponível em: www.ee.usp.br/reeusp/. Acesso em: 23/abr/2018.

PRADO, Marta Lenise do et al . Arco de Charles Maguerez: refletindo estratégias de metodologia ativa na formação de profissionais de saúde. Esc. Anna Nery, Rio de Janeiro , v. 16, n. 1, p. 172-177, Mar. 2012.

PRETTO, Nelson De Luca; RICCIO, Nicia Cristina Rocha. A formação continuada de professores universitários e as tecnologias digitais. Educar, Editora UFPR. Curitiba, n. 37, p. 153-169, maio/ago. 2010.

PRYJMA, Marielda Ferreira; OLIVEIRA. Oséias Santos de. O desenvolvimento profissional dos professores da educação superior: reflexões sobre a aprendizagem para a docência.

Revista Educ. Soc.

RATINAUD, P. IRAMUTEQ: Interface de R pour les Analyses Multidimensionnelles de Textes et de Questionnaires [Computer software]. Retrieved from http://www.iramuteq.org. 2009.

SEBOLD, L.F; CARRARO; T.E. A prática pedagógica para o docente em enfermagem: uma revisão integrativa da literatura. Revista Enferméria Global. Vol. 10, Núm. 2. 2011.

STANO, Rita de Cássia M. T.. O caminho de um grupo de formação continuada docente: do compartilhamento de práticas docentes para uma pedagogia da e para a autonomia. Educ. rev., Curitiba, n. 57, p. 275-290, Sept. 2015.

VINCENZI, Ariana De. co). Concepciones de enseñanza y su relación con las prácticas docentes: un estudio con profesores universitarios. Educación y Educadores, vol. 12, núm. 2, agosto, 2009, pp. 87-101.

VOSGERAU, Dilmeire Sant'Anna Ramos; ORLANDO, Evelyn de Almeida; MEYER, Patricia. Produtivismo acadêmico e suas repercussões no desenvolvimento profissional de professores universitários. Educ. Soc., Campinas, v. 38, n. 138, p. 231-247, Jan. 2017. 
' Este estudo integra uma pesquisa maior que tem como objetivo identificar e compreender as representações sociais, dos professores iniciantes de três universidades do Triângulo Mineiro, sobre formação e desenvolvimento profissional docente na educação superior.

ii O R é uma linguagem orientada a objetos que aliada a um ambiente integrado permite a manipulação de dados, realização de cálculos e geração de gráficos. 